\title{
The Effect of Psychological Resilience on Employees' Burnout Level
}

Tahir Akgemci

Selcuk University, Turkey

\section{Tahir Demirsel}

Selcuk University, Turkey

Özlem Kara

Selcuk University, Turkey

\section{Doi:10.5901/ajis.2013.v2n11p122}

Abstract

Stress and burn-out among academics has been the focus of a number of studies over the years. Results have varied considerably, especially regarding the incidence of burn-out. This study highlights the burnout levels of academics in terms of some demographic variables such as age, marital status, number of children, academic title and years of service and analyses the connection between psychological resilience and the burnout level of academics working in Selcuk University in Turkey. In this research burnout syndrome has been discussed in three dimensions. These are emotional exhaustion, depersonalization and lower personal accomplishment. The survey technique has been applied as the data gathering method in this research. The study has taken place in the Faculty of Economics and Administrative Sciences in Selcuk University in Konya-Turkey. The questionnaire has been distributed to 60 randomly selected academics. 44 of these questionnaires have been returned and evaluated. According to the findings, some demographic variables have positive and some have negative effects on the dimensions of burnout syndrome. Moreover, as a result of the regression analysis, a negative linear relationship between psychological resilience and the burnout levels of academics is observed. At the end, some suggestions in order to prevent burnout syndrome and increase the level of resilience will be declared and some implications for academics will be addressed.

Keywords: Psychological resilience, Burn-out syndrome, Demographic variables, Academics.

\section{Introduction}

Individuals in the world of post-industrial business life have been working under high levels of stress because of so many reasons like different roles installed by work life and personal life, the pressures of social and economic conditions, competitive pressures and employers' expectations of high productivity and fast service. Under these circumstances, it is inevitable to continuously encounter problems for the employees. Therefore the ones who cannot cope sufficiently with high stress and problems, ultimately face "Burnout Syndrome".

Burnout affects people both personally and professionally regardless of occupation. In recent years the conception of burnout has been modified, and above all it has begun to be treated as a phenomenon which affects members of many professions, and not only those of the human service professions: burnout is described as a crisis in one's relationship with work in general (Chirkowska-Smolak and Kleka, 2011: 87).

Academics routinely spend lots of hours reading, writing, lecturing, and solving countless problems that are sustained by their students and institutions. This level of involvement can be emotionally draining and coupled with working environments that are often highly stressful has the potential to lead to burnout (Maslach et. al, 2001: 397). This emotional involvement is the primary reason of the increasing rate of burnout among academic staff in an educational institution depending on the country's working conditions.

Feelings of emotional exhaustion are a key aspect of the burnout syndrome. Academics, after intensive interaction on a prolonged basis, may find their emotional energies drained. They soon realize they can no longer give of themselves as they were able to earlier in their careers. The second aspect of the burnout syndrome is depersonalization. Here the academics may develop negative cynical attitudes toward students. They can convey such attitudes in many ways, including the use of derogatory labels. A third aspect of burnout is the loss of feeling of accomplishment from the job. This 
is extremely important in education, since academics enter the profession not for financial reward, but because they feel they can help students. When they perceive themselves as no longer making a meaningful contribution through their work, they evaluate themselves negatively (Schwab, 1983: 21-22).

Academics experiencing these feelings of burnout can have a detrimental effect on their colleagues, their students, and the reputation of the school where they work. Studies have suggested that people experiencing burnout are more likely to leave their jobs, call in sick, increase their use of alcohol and drugs, and have family and marital conflicts (Maslach and Jackson, 1981: 102). As a result, this process lead up to employee turnover, reduction in quality and quantity of work, and conflict in the home and work environment.

It has been reported that most people among academics may have been exposed to burnout during the course of their lives (Ozer et. al, 2003: 52) and almost everyone will eventually be confronted with pain and disorientation following the burnout syndrome (Bonanno et. al, 2005: 827). Despite these stressful life experiences, many people manage to endure and overcome the temporary upheaval of these traumatic events remarkably well, with no apparent disruption in their ability to function at work or in close relationships. This situation is called as "resilience".

One's capacity to maintain a pattern of low distress and adequate functioning following stressful experiences is known as resilience (Bonanno et. al, 2005: 827). Individuals found to exhibit psychological resilience, are thought to possess a number of specific personal attributes that contribute to their ability to approach difficult situations in a way that adds to their resilient nature, and serves to continually expand their personal and psychological strength. Tugade and Fredrickson (2004) proposed that what may set people with high levels of psychological resilience apart from those with low levels of psychological resilience is a capacity to learn from the setbacks of life and to utilize that knowledge as a means of coping more effectively in the future (p. 321). Accordingly, by developing resilience, academics may overcome the stress and uncertainty they are facing during their career in the academic environment.

\section{The Concept of Burnout Syndrome}

The value of emotional and physical load differs in the process of professional activity. At low loads the body selfregulates, while at high loads it requires certain ways to restore health and work efficiency. It is established that specialists who experience intensive contact with other people as a part of their professional activity are primary subjects to the syndrome of professional burn-out (Dombrovskis, et. al, 2011: 98).

The concept of professional burnout was first examined by Herbert Freudenberger in 1974. While Freudenberger did not offer a definition for the phenomenon of burnout at that time, he was the first to look at burnout in terms of the physical and behavioral effects it had on individuals. In the early 1970s, the term "burnout " was primarily associated with individuals who were substance abusers and no longer cared about anything but their drug of choice (Lambie, 2006: 32).

Burnout is defined by Freudenberger (1980) as "someone in a state of fatigue or frustration brought about by devotion to a cause, way of life, or relationship that failed to produce the expected reward" (p. 13). Those suffering from burnout do not perceive themselves as angry, rigid, or cynical, but believe they have worked harder, given more, and are unappreciated (Freudenberger, 1977: 26).

Burn out is formally defined as a state of physical, emotional, and mental exhaustion caused by long-term involvement in situations that are emotionally demanding. People experience burn out as a gradual erosion of their spirit and zest as a result of the daily struggles and chronic stresses that are typical of everyday life and work - too many pressures, conflicts, demands, and too few emotional rewards, acknowledgments, and successes. Stress, in and of itself, does not cause burn out. People are often able to flourish in stressful, demanding careers if they feel valuable and appreciated and that their work has significance. They burn out when their work has no meaning and stress continuously outweighs support and rewards (Harrison, 1999: 25).

As defined by Christina Maslach, "job burnout is a psychological syndrome that involves a prolonged response to stressors in the workplace. Specifically, it involves the chronic strain that results from an incongruence, or misfit, between the worker and the job (Maslach, 2003: 189). Burnout is a continuous variable, ranging from low to high degrees of feeling (Maslach et. al, 2001: 398). Burnout is not viewed as a dichotomous variable being either present or absent, but is exhibited somewhere within the range from low to high degrees of feeling. Maslach (1981) found three elements to describe her model of burnout: (a) emotional exhaustion; (b) depersonalization; and (c) personal accomplishment. These elements coexist while being viewed individually as a step-by-step process, with emotional exhaustion being the key variable in assessing burnout (p. 101).

Maslach and Jackson (1981) developed the Maslach Burnout Inventory which includes three components of burnout: emotional exhaustion, depersonalization, and personal accomplishment, using a 22 item questionnaire. From 
these items three subcale scores (one score for each burnout component) and a total burnout score are obtained. One's level of burnout is determined based on the combination of scores on the three burnout subscales (p. 102).

Certain job characteristics are known to contribute to burnout. These include high workload; time pressure; conflicting demands on the job; lack of adequate information to do the job well; lack of social support, especially from supervisors; and lack of feedback. Individuals who have little influence on decision-making tend to experience burnout more often than those who have more influence. Maslach and others have developed a useful theoretical model that considers how well or poorly a person fits their job -sometimes referred to as "job-person fit". The more doubtful the fit, the more likely the person will experience burnout (Maslach et. al, 2001: 401).

Researches reveal that burned out human service professionals, including academics, have had and perhaps are still having a hard time. Although the fit between them and their job has been disrupted, they continue their work, and, by doing so, harm their own health and the well-being of their clients (Evers and Tomic, 2003: 1). But if they develop a resistance to burnout, secure their job-person fit and manage to stay resilient they may pursue their normal lives.

\section{The Concept of Psychological Resilience}

Resiliency is one component of psychological well-being that is particularly related to the acceptance of burnout syndrome. Resiliency (or hardiness) is an important factor in sustained positive well-being (Block and Kremen, 1996: 350). While the study of coping strategies and hardiness is not a new concept, resilience specific research did not begin until the 1970s with a focus on children who not only survived high stress environments, but grew up to live normal healthy lives (Wagnild, 2009: 106).

Resilience is commonly used to describe personal hardiness, defined as an ability to achieve personal growth in the face of adversity. Resilience is also defined as the ability to bounce back to a level of functioning that is equal to or greater than before a crisis (Boss, 2006: 47). From a social science perspective, Masten et al. (1990) defined resilience as "the process of, capacity for, or outcome of successful adaptation despite challenging or threatening circumstances" (p. 426).

Psychological resilience is a dynamic process wherein individuals display positive adaptations (i.e., competencies) despite experiences of significant adversity or trauma (Masten and Coatsworth, 1998). In order to fully understand what psychological resilience 'is', however, one must further define the terms of 'adversity' and 'positive adaptations'. 'Adversity' (or risk) refers to negative life circumstances associated with adjustment difficulties (Luthar and Cicchetti, 2000: 859). Meanwhile, a 'positive adaptation' refers to for example success in meeting the expectations about working life (Masten and Coatsworth, 1998: 207).

Tugade and Fredrickson (2004) reported that people who are able to move on despite negative stressors do not demonstrate "luck" on the part of those successful individuals, but demonstrates a concept known as "resilience". Tugade and Fredrickson defined psychological resilience as "effective coping and adaptation although faced with loss, hardship, or adversity"(p. 321).

Resilience is believed by some to be a matter of inherent traits, while others prescribe to the theory it is learned through interaction and experiences with others and our environment. More recent research points to a resilience developing as a result of a combination of both traits and learning (Jacelon, 1997: 123).

The theory then is that resilience is a skill that can be learned, and a learned skill can be built upon with a combination of experience and education. A resilient person can learn to achieve positive outcomes through skilled preparation, confidence and perseverance despite the existence of possible threats, even serious ones (Phillips, 2008: 46).

Almost all people experience stressful situations that leave them vulnerable, but whether these individuals are crushed or strengthened by adverse situations, depend on the person's level of resilience. Youssef and Luthans (2007: 779) state that there are several unique characteristics that distinguish resilience from other psychological capacities. Resilience is more linked to the need to take both proactive and reactive measures in the face of adversity. A person's capacity to be resilient promotes the recognition and acknowledgement of adversities, allowing the affected individual the time, energy and resource investment to recover, rebound, and return to an equilibrium point.

Closely related to coping, resilience is considered more of a proactive, even preventative action that an individual engages in, which prepares them to more effectively deal with stress (Ginsburg, 2011: 4). Therefore, resilience consists of a balance between stress and the ability to cope. Resilience is dynamic, and it depends on life context. Resilience is developmental and when it is successfully demonstrated, it strengthens a person's competence (Greene, et. al, 1986: 248). 
In this paper the term resilience as an umbrella concept, referring to both outcomes and processes, will be used. Resilience will particularly be used in terms of academic resilience, referring to academics who are successful, despite obstacles that prevent the majority of other academics with similar obstacles from succeeding. The fact that it can include both a process and an outcome, makes research on resilience as a possible predictor of academic success, rather valuable, because it is particularly during the process phase when supportive interventions by the institution can contribute to the envisaged successful outcomes of academic performance (Niemann and Kotze, 2012: 306).

\section{Methodology}

The objective of this research is to reveal the effect of the psychological resilience on the burn-out levels of the academics working in a faculty of Selcuk University. In this research burn-out syndrome has been discussed in three dimensions. These are emotional exhaustion, depersonalization and lower personal accomplishment (Maslach and Jackson, 1982). In this research the effect of the psychological resilience on the burn-out levels of the employees has been examined. The survey technique has been applied as a data gathering method in this research. The survey consists of three parts. In the first part, demographic features of the employees have been determined. The second part includes questions that measure employees' psychological resilience level. The questions in this part have been prepared by adapting the Friborg et al. (2005)'s scale by Basım and Çetin (2011). The third part of the survey includes questions about burn-out syndrome. The questions in this part have been taken from the scale prepared by adapting the Maslach and Jackson (1982)'s scale by Ergin (1992). All the statements in the survey are answered in the form of 5-point Likert scale. The study has taken place in the Faculty of Economics and Administrative Sciences in Selcuk University in Konya Turkey. The questionnaire has been distributed to 60 randomly selected academics. 44 of these questionnaires have been returned and evaluated. Hypotheses of the study are as follows:

$\mathrm{H} 1=$ There are significant differences between the levels of burnout according to age.

$\mathrm{H} 2=$ There are significant differences between the levels of burnout according to the marital status.

$\mathrm{H} 3=$ There are significant differences between the levels of burnout according to the number of children.

$\mathrm{H} 4=$ There are significant differences between the levels of burnout according to the academic title

$\mathrm{H} 5=$ There are significant differences between the levels of burnout according to the years of service

$\mathrm{H} 6=$ Psychological resilience has a significant effect on emotional exhaustion.

$\mathrm{H} 7=$ Psychological resilience has a significant effect on depersonalization.

$\mathrm{H8}=$ Psychological resilience has a significant effect on lower personal accomplishment.

Data obtained from the questionnaires were analyzed by using SPSS 20 software package. Cronbach's alpha was used to determine the level of reliability of the questionnaire. In order to evaluate the demographic data of the study, frequency distribution of employees was used. The mean and standard deviation were used to interpret the results of the scale.Independent t-test and oneway ANOVA test were used to find out whether employees have differences in terms of demographic variables. Finally, regression analysis was performed to determine the relationships between the variables.

\section{Research Findings}

In this section research findings will be summarized under three different titles. These are: the characteristics of the sampling, variance analysis and regression analysis.

\subsection{Characteristics of the Sampling}

The demographic characteristics of the academic staff evaluated in the context of the research are given in Table 1.

Table 1: The Demographic Characteristics of the Sample

\begin{tabular}{|c|c|c|c|c|c|c|c|c|}
\hline Characteristics & f & $\%$ & Characteristics & f & $\%$ & Characteristics & f & $\%$ \\
\hline Age & & & Marital Status & & & Nr. of Children & & \\
$20-30$ & 32 & 72,7 & Bachelor & 28 & 63,6 & None & 33 & 75,0 \\
$31-40$ & 11 & 25,0 & Married & 16 & 36,4 & 1 & 10 & 22,7 \\
Over 40 & 1 & 2,3 & & & & over 1 & 1 & 2,3 \\
\hline Total & 44 & 100,0 & Total & 44 & 100,0 & Total & 44 & 100,0 \\
\hline Characteristics & $\mathrm{f}$ & $\%$ & Characteristics & $\mathrm{f}$ & $\%$ & & & \\
\hline
\end{tabular}




\begin{tabular}{|c|c|c|c|c|c|c|c|c|}
\hline Academic Title & & & Years of Service & & & & & \\
Res. Ass. & 39 & 88,6 & $1-5$ & 34 & 77,3 & & & \\
Ph.D. & 2 & 4,5 & $6-10$ & 5 & 11,4 & & & \\
Ass. Prof. & 3 & 6,8 & over 10 & 5 & 11,4 & & & \\
\hline Total & 44 & 100,0 & Total & 44 & 100,0 & & & \\
\hline
\end{tabular}

\subsection{Variance Analysis}

When participants' responses to the statements describing emotional exhaustion variable are compared with the age groups by oneway Anova test, there is a significant difference $(F=4.776, p<0.05)$. But there is not any significant differences for depersonalization ( $F=1.722, p>0.05)$ and lower personal accomplishment $(F=0.795, p>0.05)$ variables.

There is not any statistically significant difference between marital status of the academic staff and the levels of burnout. According to the results of one sample t test performed to find out the variances between the sub-dimensions of burnout and marital status of the participants, there is not any significant variance for emotional exhaustion ( $F=0.091$, $p>0.05)$, depersonalization ( $F=2.547, p>0.05)$ and lower personal accomplishment $(F=2.774, p>0.05)$.

Again no statistically significant differences were found between the number of children that academic staff have and the levels of burnout: emotional exhaustion ( $F=2.614, p>0.05)$, depersonalization $(F=0,654 p>0.05)$ and lower personal accomplishment ( $\mathrm{F}=0.146 \mathrm{p}>0.05)$.

When the academic title variable is examined through oneway Anova test, only the sub-dimension of emotional exhaustion has a significant difference $(F=8.788, p<0.05)$. On the other hand, neither depersonalization $(F=2.589$, $\mathrm{p}>0.05)$ nor lower personal accomplishment $(\mathrm{F}=1.026 \mathrm{p}>0.05)$ has a statistically significant difference.

Considering the variable of academics' years of service, it was seen that there is not any statistically significant differences in the levels of burnout emotional exhaustion $(F=0.047, p>0.05)$, depersonalization $(F=0,751, p>0.05)$ and lower personal accomplishment $(\mathrm{F}=0.464, \mathrm{p}>0.05)$.

\subsection{Regression Analysis}

When dealing with the functional form of the relationship between the variables regression analysis is used. In other words, how much the independent variable explain the dependent one is determined by regression analysis. In this context, the effect of psychological resilience on the level of burnout was found out through this way.

Table 2: Results of the Regression Analysis between Psychological Resilience and Burnout

\begin{tabular}{|c|c|c|c|c|c|c|c|c|c|}
\hline \multirow{3}{*}{$\begin{array}{c}\text { Independent } \\
\text { Variables }\end{array}$} & \multicolumn{9}{|c|}{ Dependent Variables } \\
\hline & \multicolumn{3}{|c|}{ Emotional Exhaustion } & \multicolumn{3}{|c|}{ Depersonalization } & \multicolumn{3}{|c|}{ Lower Personal Accomplishment } \\
\hline & $\beta$ & $\mathrm{t}$ & $\mathrm{p}$ (Sig.) & $\mathrm{B}$ & $\mathrm{t}$ & $\mathrm{p}$ (Sig.) & $\beta$ & $\mathrm{t}$ & $\mathrm{p}$ (Sig.) \\
\hline Psychological Resilience & $-0,511$ & $-2,648$ & 0,000 & $-1,010$ & $-4,710$ & 0,000 & $-0,707$ & $-5,199$ & 0,000 \\
\hline & $\begin{array}{c}F: \\
7,012\end{array}$ & \multicolumn{2}{|c|}{ Sig.a: 0,011} & $\begin{array}{c}F: \\
22,186\end{array}$ & \multicolumn{2}{|c|}{ Sig. a: 0,000} & $\begin{array}{c}\mathrm{F}: \\
27,029\end{array}$ & \multicolumn{2}{|c|}{ Sig. a: 0,000} \\
\hline R2 & \multicolumn{3}{|c|}{0,143} & \multicolumn{3}{|c|}{0,346} & \multicolumn{3}{|c|}{0,392} \\
\hline
\end{tabular}

\subsubsection{Emotional Exhaustion}

At the end of the analysis sig.(p) value in the Anova table is 0.000 . Since $p=0,000<\alpha=0,05$, model is statistically significant at $95 \%$ confidence interval. Coefficient of determination was found to be R2 $=0,143$. Accordingly, it can be said that the $14.3 \%$ of the differences in emotional exhaustion can be explained as due to psychological resilience. However the rest $85.7 \%$ depends on other changes. A one-unit increase in psychological resilience causes $51.1 \%$ decrease in the dimension of emotional exhaustion. In this context, a negative correlation was found between resilience and emotional exhaustion.

\subsubsection{Depersonalization}

At the end of the analysis sig.(p) value in the Anova table is 0.000 . Since $p=0,000<\alpha=0,05$, model is statistically significant at $95 \%$ confidence interval. Coefficient of determination was found to be R2 $=0,346$. Accordingly, it can be 
said that the $34.6 \%$ of the differences in depersonalization can be explained as due to psychological resilience. However the rest $65.4 \%$ depends on other changes. A one-unit increase in psychological resilience causes $101.1 \%$ decrease in the dimension of depersonalization. In this context, a negative correlation was found between resilience and depersonalization.

\subsubsection{Lower Personal Accomplishment}

At the end of the analysis sig.(p) value in the Anova table is 0.000 . Since $p=0,000<\alpha=0,05$, model is statistically significant at $95 \%$ confidence interval. Coefficient of determination was found to be R2 =0,392. Accordingly, it can be said that the $39.2 \%$ of the differences in lower personal accomplishment can be explained as due to psychological resilience. However the rest $60.8 \%$ depends on other changes. A one-unit increase in psychological resilience causes $70.7 \%$ decrease in the dimension of lower personal accomplishment. In this context, a negative correlation was found between resilience and lower personal accomplishment.

\section{Conclusion}

Psychological resilience negatively affects burnout according to the results of similar researches. A linear negative relationship can be observed between them. An increase in the level of psychological resilience causes a decrease in the level of burnout. Accordingly we have seen that as the level of academic staff's psychological resilience increases, their level of burnout decreases.

Excessive stress, by causing depressions and illnesses, reduces the enthusiasm, desire, efficiency and effectiveness of the working individuals. If not coped with, stress decreases the productivity and ability to enjoy life and finally burnout syndrome begins. Individuals in time go away from close relations and become withdrawn persons. If resilience does not step in the process, burnout may not be coped with. In the organizations developing coping strategies for stress and burnout by increasing the employees' level of psychological resilience, costs caused by labor loss may decrease and the quality of work and productivity may increase. Individuals with higher level of psychological resilience undoubtedly will become much more efficient and successful. Therefore, the development of academics' psychological resilience will provide universities with significant benefits.

At the same time, as the physiological resilience increases, people secrete various hormones. These are serotonin, adrenaline or endorphins which make such people happier and energetic. In this way, an individual explores the inherent power to cope with burnout, becomes a motivated person and finds the solution for problems rather than to escape them.

When faced with stress, resilient individuals evaluate this situation as an adaptive process and maintain their mental health by using effective coping strategies. Resilient and non-resilient individuals react differently to the same stress factors. Resilient individuals reduce the risks of burnout by controlling the factors that creates stress and coping with them.

As a result, we can say that psychological resilience by helping individuals in combating stress helps them to manage difficult conditions. In this way, they commit much more strongly to their jobs and organizations. The excess of positive emotions gives people the ability to quickly recover in stressful events and contributes them to become motivated by providing a more flexible thinking manner.

\section{References}

Block, J. and Kremen, A. M. (1996). IQ and ego-resiliency: Conceptual and empirical connections and separateness. Journal of Personality and Social Psychology, 70, 349-361.

Bonanno, G. A., Moskowitz, J. T., Papa, A. and Folkman, S. (2005). Resilience to loss in bereaved spouses, bereaved parents, and bereaved gay men. Journal of Personality and Social Psychology, 88(5), 827-843.

Boss, P. (2006), Loss, Trauma, and Resilience: Therapeutic Work With Ambiguous Loss, W. W. Norton \& Company.

Chirkowska-Smolak, T. and Kleka, P. (2011). The Maslach Burnout Inventory-General Survey: validation across different occupational groups in Poland, Polish Psychological Bulletin, Vol. 42 (2), 86-94.

Dombrovskis, V., Guseva, S. and Murasovs, V. (2011). Motivation to Work and the Syndrome of Professional Burnout among Teachers in Latvia, Procedia - Social and Behavioral Sciences, 29, 98 - 106.

Evers, W. J. G. and Tomic, W. (2003). Students' perceptions of the incidence of burn-out among their teachers, Research in Education; May 2003; 69; 1-16.

Freudenberger, H. (1977). Burn-out: The organizational menace, Training \& Development Journal, 31(7), $26-27$. 
Freudenberger, H. (1980). Burnout: The high cost of high achievement. Garden City, NY: Anchor Press.

Ginsburg, K. R. (2011). Building Resilience in Children and Teens: Giving Kids Roots and Wings, American Academy of Pediatrics; Second Edition edition.

Greene, R., Johnson, D. and Campbell, W. (1986). Teacher job satisfaction and teacher job stress: School size, age and teaching experience. Education, 2, 247-252.

Harrison, B. J. (1999). Are you destined to burn out?, Fund Raising Management; 30, 3, 25-27.

Jacelon, C. S. (1997). The trait and process of resilience. Journal of Advanced Nursing, 25, 123-129.

Lambie, G. (2006). Burnout prevention: A humanistic perspective and structured group supervision activity. Journal of Humanistic Counseling: Education and Development, 45, 32-45.

Luthar, S., and Cicchetti, D. (2000). The construct of resilience: Implications for interventions and social policies. Development and Psychopathology, 12, 857-888.

Maslach, C. (2003). Job Burnout: New Directions in Research and Intervention, Current Directions in Psychological Science (WileyBlackwell), 12 (5), 189-192.

Maslach, C., Schaufeli, W. B. and Leiter, M. P. (2001), Job Burnout, Annual Review of Psychology 52, 397-422.

Maslach, C. and Jackson, S. E. (1981). The measurement of experienced burnout. Journal of Occupational Behavior, 2, 99-115.

Masten, A. S. and Coatsworth, J. D. (1998). The development of competence in favourable and unfavourable environments: Lessons from successful children. American Psychologist, 53, 205-220.

Masten, A. S., Best, K. M. and Garmezy, N. (1990). Resilience and development: Contributions from the study of children who overcome adversity. Development and Psychopathology, 2, 425-444.

Niemann, R. and Kotze, T. (2012). Researching Resilience as a Psychological Resource Capacity: A Possible Predictor of Students' Academic Experience at a South African University, Proceedings of the 11th European Conference on Research Methods, University of Bolton, UK, 28-29 June 2012, 304-312.

Ozer, E. J., Best, S. R., Lipsey, T. L. and Weiss, D. S. (2003). Predictors of posttraumatic stress disorder and symptoms in adults: A meta-analysis. Psychological Bulletin, 129, 52-73.

Phillips, G. (2008). Resilience in practice interventions. Child Care in Practice, 14(1), 45-54.

Schwab, R. L. (1983). Teacher Burnout: Moving beyond "Psychobabble", Theory into Practice, Vol. 22, No. 1, Coping with Stress, $21-26$.

Tugade, M. M. and Fredrickson, B. L. (2004). Resilient individuals use positive emotions to bounce back from negative emotional experiences, Journal of Personality and Social Psychology, Vol 86(2), 320-333.

Wagnild, G. M. (2009). A review of the resilience scale. Journal of Nursing Measurements, 17(2), 105-113.

Youssef, C.M. and Luthans, F. (2007) Positive organizational behaviour in the workplace: The impact of hope, optimism and resilience, Journal of Management, Vol 33, 774-800. 